\title{
EVALUASI PEMENUHAN KEBUTUHAN TEMPAT PARKIR BAGI SISWA DAN GURU PADA SEKOLAH DASAR DI SURAKARTA
}

\author{
Teguh Yuono \\ Program Studi Teknik Sipil, Fakultas Teknik, Universitas Tunas Pembangunan Surakarta \\ teguhyuono.ty@gmail.com \\ Suryo Handoyo \\ Program Studi Teknik Sipil, Fakultas Teknik, Universitas Tunas Pembangunan Surakarta \\ suryoyoyot@gmail.com
}

\begin{abstract}
Abstrak
Pendidikan memegang peranan yang sangat vital dalam perkembangan sebuah bangsa. Bangsa yang maju dapat dilihat dari tingkat pendidikan penduduknya, semakin maju sebuah bangsa semakin tinggi juga tingkat pendidikan penduduknya. Pemerintah dari tahun ke tahun terus meningkatkan alokasi anggaran negara untuk meningkatkan kualitas pendidikan. Pembangunan gedung sekolah beserta prasarana pendukungnya sebaiknya juga memperhatikan kebutuhan tampungan sarana transportasi yang digunakan oleh siswa dan guru, baik itu berupa sepeda, sepada motor maupun mobil. Dari pengamatan yang ada kenyataannya banyak sekolahan yang belum memprioritaskan penyediaan tempat parkir yang memadai. Sehingga perlu dilakukan penelitian letak sekolah dalam sebuah permukiman, kondisi tempat parkir yang ada dan pemenuhan kebutuhan parkir. Lokasi penelitian yaitu sekolah dasar di Kota Surakarta. Dalam penelitian dibuat rancangan penelitian sebagai berikut : 1). penyiapan bahan dan peralatan. 2).survei lapangan,wawancara, pengamatan, foto dokumentasi dilanjutkan pengukuran dan dibuat sket. 3). pembuatan gambar peta situasi keberadaan sekolah dan permukiman sekitarnya. 4). pengambaran denah sekolahan dan tempat parkir. 5). analisis kondisi tempat parkir yang ada, menghitung kebutuhan tempat parkir dan mengambar denah tempat parkir yang ideal. Hasil penelitian didapatkan 1). letak sekolahan terhadap permukiman, $10 \%$ sekolah cukup dekat, $20 \%$ dekat dan $70 \%$ sangat dekat. 2). kondisi tempat parkir bagi siswa yang membawa sepeda ontel kurang memadai, prosentase kondisi tempat parkir pada lokasi penelitian adalah 20\% kondisi kurang, 60\% kondisi sedang, 20\% kondisi baik. 3). kebutuhan lahan untuk tempat parkir tercukupi dengan pengaturan parkir yang baik. Rata-rata dalam satu sekolahan membutuhkan lahan parkir seluas $129 \mathrm{~m}^{2}$, dengan kapasitas untuk sepeda 37 unit, 13 sepeda motor dan 2 mobil.
\end{abstract}

Kata kunci: permukiman, sekolah, tempat parkir.

\begin{abstract}
Education plays a very vital role in the development of a nation. A developed nation can be seen from the level of education of its population, the more advanced a nation the higher the level of education of its population. The government continues to increase the allocation of the state budget from year to year to improve the quality of education. The construction of school buildings and their supporting infrastructure should also pay attention to the needs of the transportation facilities used by students and teachers, both in the form of bicycles, motorbikes or cars. From the observations, the reality is that many schools have not prioritized the provision of adequate parking spaces. The research location is elementary school in Surakarta City. 1). preparation of materials and equipment. 2). field surveys, interviews, observations, photos of documentation, measurements and sketches making. 3). making an image map of the situation of the existence of the school and the surrounding settlements. 4). depiction of school plans and parking lots. 5). analyzing the condition of the existing parking space, calculating the need for a parking space and drawing an ideal parking plan.
\end{abstract}


The results of the study were obtained 1). where schools are located in settlements, $10 \%$ of schools are near enough, $20 \%$ are near and $70 \%$ are very near. 2). parking conditions for students who bring bicycles are inadequate, the percentage of parking conditions at the study site is $20 \%$ less conditions, $60 \%$ moderate conditions, $20 \%$ good conditions. 3). the need for parking space is fulfilled with good parking arrangements. On average in one school requires $129 \mathrm{~m}^{2}$ of parking space, with capacity for 37 units of bicycles, 13 motorbikes and 2 cars.

Keywords: residential areas, schools, parking lots.

\section{PENDAHULUAN}

Pendidikan memegang peranan yang sangat vital dalam perkembangan sebuah bangsa. Bangsa yang maju dapat dilihat dari tingkat pendidikan penduduknya, semakin maju sebuah bangsa semakin tinggi juga tingkat pendidikan penduduknya. Pemerintah dari tahun ke tahun terus meningkatkan alokasi anggaran negara untuk meningkatkan kualitas pendidikan. Peningkatan gaji guru dan pemberian sertifikasi merupakan salah satu cara untuk meningkatkan kesejahteraan guru sehingga proses pembelajaran diharapkan dapat terus meningkat mutunya. Pembangunan sarana sekolah baik ruang kelas, labolatorium, tempat ibadah, kantin, kantor guru terus mendapatkan anggaran yang cukup besar. Kurikulum yang terus diperbaharui yang berdasarkan minat dan bakat anak didik terus berkembang dengan baik.

Pembangunan gedung sekolah beserta kelengkapannya sebaiknya juga memperhatikan kebutuhan tampungan sarana transportasi yang digunakan oleh siswa dan guru, baik itu berupa sepeda, sepada motor maupun mobil. Dalam kesehariannya untuk murid-murid sekolah dasar yang lokasi sekolahnya tidak jauh dari tempat tinggalnya biasanya berjalan kaki atau mengunakan sepeda ontel untuk menuju sekolah. Dari pengamatan yang ada kenyataannya banyak sekolahan yang belum memprioritaskan penyediaan tempat parkir yang memadai. Berdasarkan latar belakang yang ada maka dapat dirumuskan permasalahan sebagai berikut :1)Bagaimana letak sekolah dalam sebuah permukiman; 2) Bagaimana kondisi tempat parkir yang ada; 3) Bagaimana pemenuhan kebutuhan parkir yang ideal.

\section{LANDASAN TEORI}

\subsection{Permukiman}

Menurut Undang-Undang no. 1 tahun 2011 tentang Perumahan dan Kawasan Permukiman bahwa permukiman adalah bagian dari lingkungan hunian yang terdiri atas lebih dari satu satuan perumahan yang mempunyai prasarana, sarana, utilitas umum, serta mempunyai penunjang kegiatan fungsi lain di kawasan perkotaan atau kawasan perdesaan.

Sekolahan atau bangunan sekolah adalah salah satu sarana untuk mendukung permukiman dalam memfasilitasi pendidikan warganya. 


\subsection{Bangunan Sekolah}

Sekolah menurut kamus besar bahasa Indonesia, sebagai sebuah lembaga atau bangunan yang digunakan untuk kegiatan belajar mengajar serta menjadi tempat memberi dan menerima pelajaran sesuai dengan tingkatannya (sekolah dasar, sekolah lanjutan, dan sekolah tinggi). Sekolah menjadi tempat dididiknya anak- anak dengan maksud mengajarkan mereka mampu menjadi manusia yang berguna bagi kemajuan bangsa.

Bangunan gedung sekolah mempunyai fungsi yang sangat penting dalam pengembangan dan pertumbuhan pendidikan suatu wilayah dan upaya mewujudkan pemerataan pembangunan pendidikan serta peningkatan kualitas dan pengembangan sumber daya manusia, dimana bangunan gedung sekolah digunakan sebagai prasarana pendidikan. Dengan tersedianya bangunan gedung sekolah akan sangat mendukung perkembangan bidang pendidikan

\subsection{Parkir}

Parkir adalah tempat pemberhentian kendaraan dalam jangka waktu pendek atau lama, sesuai dengan kebutuhan pengendara. Parkir merupakan salah satu unsur prasarana transportasi yang tidak terpisahkan dari sistem jaringan transportasi, sehingga pengaturan parkir akan mempengaruhi kinerja suatu jaringan.

Parkir juga diartikan sebagai suatu keadaan tidak bergerak suatu kendaraan yang tidak bersifat sementara dengan pengemudi meninggalkannya atau berhenti cukup lama untuk menaikkan dan menurunkan muatan (Pedoman Parkir Tahun 1998). Sedangkan menurut Keputusan Direktorat Jendral Perhubungan Darat Nomor 272 tahun 1996 tentang Pedoman Teknis Penyelenggaraan Fasilitas Parkir, parkir adalah keadaan tidak bergerak suatu kendaraan yang ditinggal pemiliknya serta bersifat sementara.

\subsection{Satuan Ruang Parkir}

Satuan Ruang Parkir (SRP) adalah ukuran luas efektif untuk meletakkan kendaraan (mobil penumpang, bus/truk, atau sepeda motor) termasuk ruang bebas dan lebar bukaan pintu. Satuan Ruang Parkir digunakan untuk mengukur kebutuhan ruang parkir, yang penetapannya didasarkan atas pertimbangan dimensi kendaraan standar untuk mobil penumpang, ruang bebas kendaraan parkir, dan lebar bukaan pintu kendaraan. Dimensi kendaraan standar untuk mobil penumpang golongan II adalah 2,5 m x 5,0 m, untuk sepeda motor adalah $0,75 \quad \mathrm{~m} \quad \mathrm{x} \quad 2,00 \mathrm{~m}$ (Direktorat Jendral Perhubungan Darat, 1996). Sedangkan untuk sepeda ontel dipakai 0,5 x 1,5 $\mathrm{m}$

\section{METODE PENELITIAN}

Menurut Data Pokok Pendidikan Dasar dan Menengah Direktorat Jenderal Pendidikan Anak Usia Dini, Pendidikan Dasar dan Pendidikan Menengah Kementerian Pendidikan dan Kebudayaan pada tahun 2019 jumlah sekolah 
dasar di Surakarta sebanyak 251 sekolah, terdiri dari 158 sekolah negeri dan 93 sekolah swasta. Dari data tersebut secara acak dipilih 10 sekolah yang menjadi lokasi penelitian, yaitu SDN Joglo No 76, SDN Mojosongo 2, SDN Sumber 2, SDN Bulukantil, SDN Tugu Jebres, SDN Sumber 5, SDN Nayu 77, SD Al Islam 3

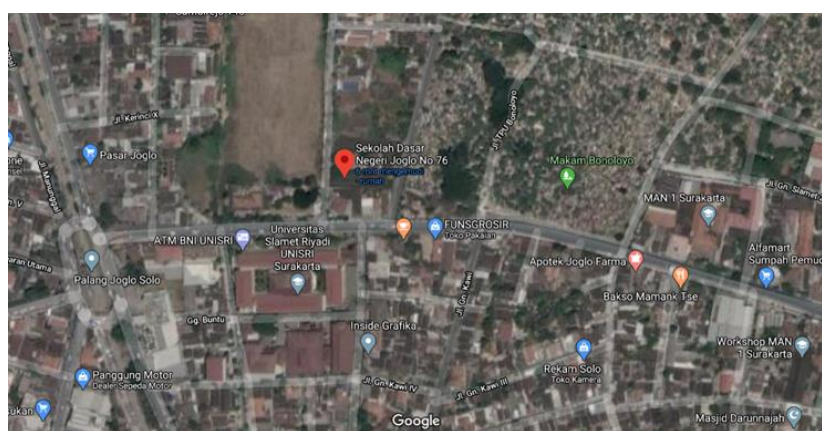

Gambar 1. Peta citra satelit lokasi SDN Joglo 76 Gebang, SDN Purwodiningratan, SD Kanisius Serengan.

Peralatan yang digunakan antara lain laser meter, meteran kecil, kamera digital, dan alat tulis. Sedangkan tatalaksana penelitian yang dilakukan sebagai berikut:

1).Kajian letak sekolah dalam sebuah permukiman. Kajian ini dimaksudkan untuk memberikan gambaran letak srategisnya sekolahan untuk mendukung permukiman dalam memfasilitasi pendidikan penduduknya.

2). Mengevaluasi kondisi parkir yang ada di sekolah. Evaluasi ini dimaksudkan untuk mengetahui kondisi parkir yang ada di sekolah meliputi luas lahan, bangunan parkir, akses dan keberfungsiannya.

3). Pemenuhan kebutuhan parkir yang ideal

Setelah mengetahui kondisi parkir yang ada, mengetahui persoalan yang dihadapi, kemudian dicarikan jalan keluar dalam pemenuhan kebutuhan parkir yang ideal

\section{PEMBAHASAN}

5.1 Kajian letak sekolah dalam sebuah permukiman.

SDN Joglo 76 Surakarta terletak di Jalan Senapan Nomer 1 Surakarta.



Gambar 2. Peta situasi SDN Joglo No 76

Berdasarkan uraian dan gambar diatas, SDN Joglo No 76 letaknya cukup dekat dengan permukiman padat penduduk terutama pada bagian selatan, sehingga membantu sekali dalam memfasilitasi pendidikan bagi penduduk sekitarnya.

Tabel 1. Kajian letak sekolah pada permukiman

\begin{tabular}{|c|c|c|c|c|c|c|}
\hline \multirow{2}{*}{ No } & \multirow{2}{*}{ Nama Sekolah } & \multicolumn{4}{|c|}{ Area yang berdekatan dengan Sekolah } & \multirow{2}{*}{$\begin{array}{c}\text { Hubungan letak } \\
\text { sekolahan dengan } \\
\text { permukiman }\end{array}$} \\
\hline & & Utara & Selatan & Timur & Barat & \\
\hline 1 & SDN Joglo No 76 & sawah & permukiman & makam & sawah & cukup dekat \\
\hline 2 & SDN Mojosongo 2 & lapangan & permukiman & permukiman & permukiman & dekat \\
\hline 3 & SDN Sumber 2 & lapangan & permukiman & permukiman & permukiman & sangat dekat \\
\hline 4 & SDN Bulukantil & permukiman & permukiman & permukiman & permukiman & sangat dekat \\
\hline 5 & SDN Tugu Jebres & permukiman & permukiman & permukiman & permukiman & sangat dekat \\
\hline 6 & SDN Sumber 5 & permukiman & permukiman & permukiman & permukiman & sangat dekat \\
\hline 7 & SDN Nayu 77 & permukiman & permukiman & permukiman & permukiman & sangat dekat \\
\hline 8 & SD Al Islam 3 Gebang & permukiman & permukiman & permukiman & permukiman & sangat dekat \\
\hline 9 & SDN Purwodiningratan & permukiman & permukiman & permukiman & permukiman & sangat dekat \\
\hline 10 & SD Kanisius Serengan & permukiman & permukiman & permukiman & permukiman & sangat dekat \\
\hline
\end{tabular}

\subsection{Mengevaluasi kondisi parkir yang ada di}

\section{sekolah}

SDN Joglo 76 Surakarta memiliki area parkir untuk sepeda ontel pada bagian belakang yang atapnya ikut tritisan kelas, memiliki tempat parkir sepeda guru yang lumayan terlindung dan halaman luas yang dapat dipakai untuk parkir 
mobil guru ataupun tamu.

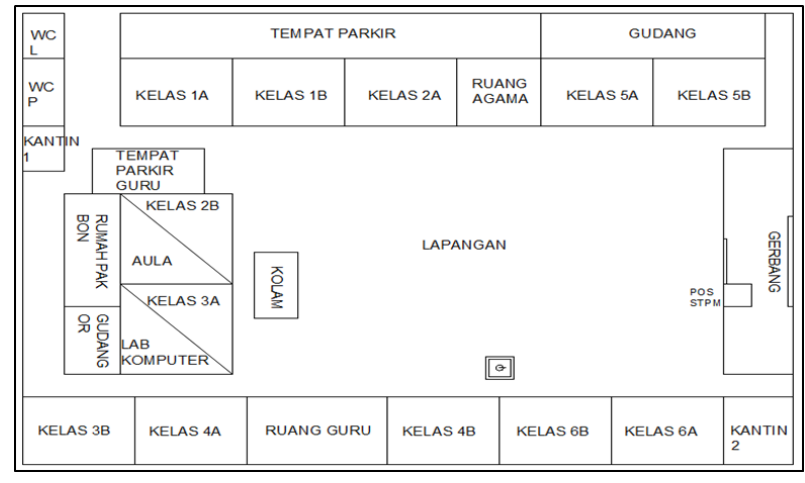

Gambar 3. Site Plan SDN Joglo No 76

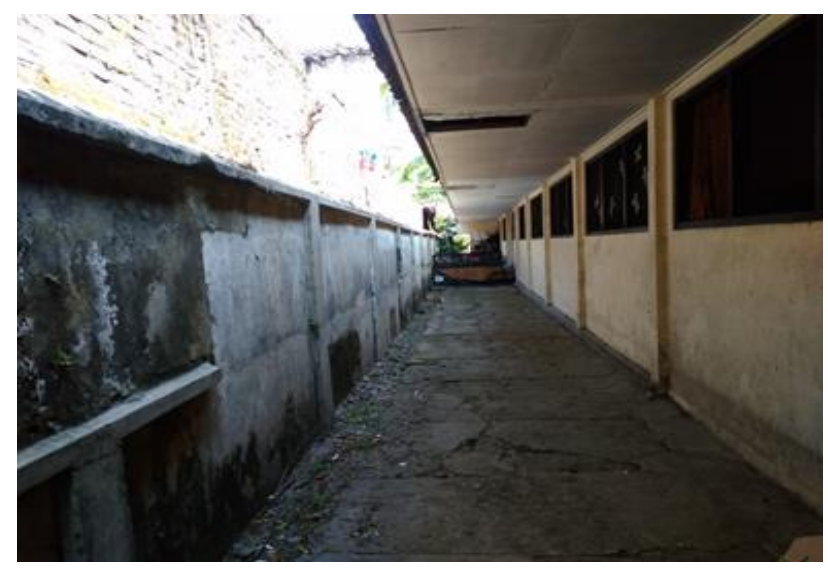

Gambar 4. Foto kondisi tempat parkir sepeda

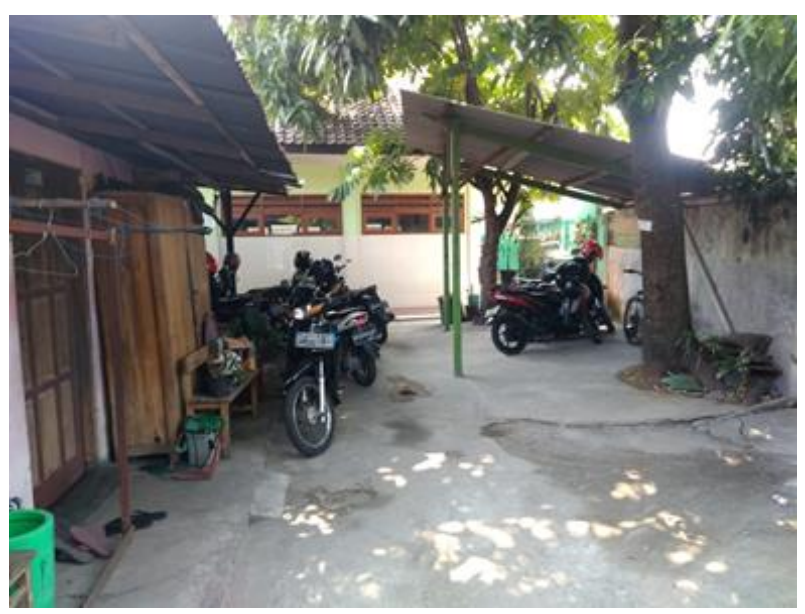

Gambar 5. Foto kondisi parkir sepeda motor

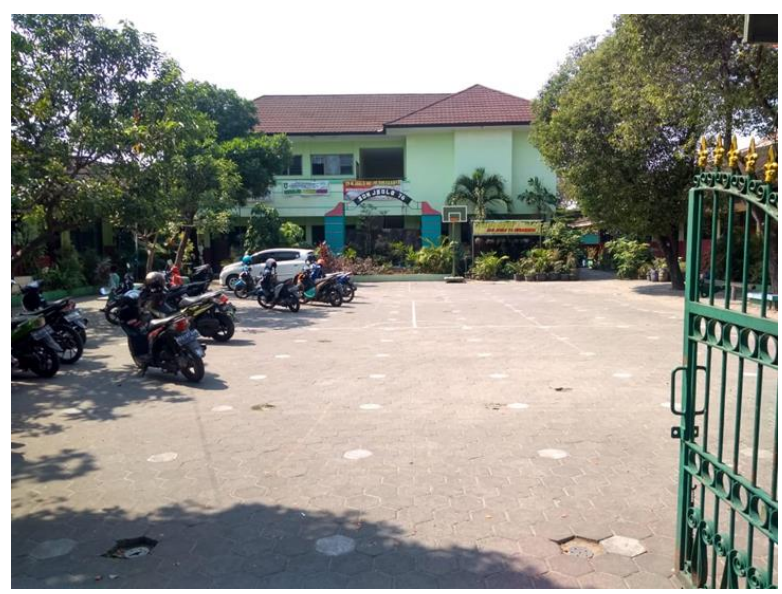

Gambar 6. Foto kondisi parkir mobil di halaman

Tabel 2. Kondisi tempat/area parkir

\begin{tabular}{|c|c|c|c|c|c|c|c|c|}
\hline \multirow[b]{2}{*}{ No } & \multirow[b]{2}{*}{ Nama Sekolah } & \multicolumn{3}{|c|}{ Keberadaan area/tempat parkir } & \multicolumn{3}{|c|}{ Kondisi area/tempat parkir } & \multirow[b]{2}{*}{$\begin{array}{c}\text { Kondisi secara } \\
\text { keseluruhan }\end{array}$} \\
\hline & & $\begin{array}{c}\text { murid } \\
\text { (sepeda } \\
\text { ontel) }\end{array}$ & $\begin{array}{c}\text { guru } \\
\text { (sepeda } \\
\text { motor) }\end{array}$ & mobil & $\begin{array}{c}\text { Sepeda } \\
\text { ontel }\end{array}$ & $\begin{array}{l}\text { Sepeda } \\
\text { motor }\end{array}$ & Mobil & \\
\hline 1 & SDN Joglo No 76 & ada & ada & ada & sedang & sedang & kurang & sedang \\
\hline 2 & SDN Mojosongo 2 & ada & ada & ada & sedang & kuang & kurang & kurang \\
\hline 3 & SDN Sumber 2 & ada & ada & ada & sedang & sedang & kurang & sedang \\
\hline 4 & SDN Bulukantil & ada & ada & ada & sedang & sedang & kurang & sedang \\
\hline 5 & SDN Tugu Jebres & ada & ada & ada & sedang & sedang & kurang & sedang \\
\hline 6 & SDN Sumber 5 & ada & ada & ada & sedang & sedang & kurang & sedang \\
\hline 7 & SDN Nayu 77 & ada & ada & ada & sedang & kurang & kurang & kurang \\
\hline 8 & SD Al Islam 3 Gebang & ada & ada & ada & baik & baik & baik & baik \\
\hline 9 & SDN Purwodiningratan & ada & ada & ada & sedang & sedang & kurang & sedang \\
\hline 10 & SD Kanisius Serengan & ada & ada & ada & baik & baik & baik & baik \\
\hline
\end{tabular}

\subsection{Pemenuhan Kebutuhan Parkir yang}

\section{Ideal}

Berikut hasil kajiannya : SDN Joglo 76 Surakarta memiliki luas lahan parkir : 252,5 $\mathrm{m}^{2}$

Kendaraan yang parkir terdiri dari sepeda 50 bh, sepeda motor $20 \mathrm{bh}$, mobil $2 \mathrm{bh}$

Tabel 3. Luas lahan parkir SDN Joglo 76

\begin{tabular}{|r|l|c|c|r|r|r|r|}
\hline No & \multicolumn{1}{|c|}{$\begin{array}{c}\text { Jenis } \\
\text { Kendaraan }\end{array}$} & $\begin{array}{c}\text { Jumlah } \\
\text { Kendaraan }\end{array}$ & Satuan & \multicolumn{2}{|c|}{$\begin{array}{c}\text { Perhitungan luas lahan yang } \\
\text { ada }\end{array}$} & Luas (m2) \\
\hline 1 & Sepeda ontel & 50 & unit & $2.50 \times$ & 61.00 & & 152.50 \\
\hline 2 & Sepeda motor & 20 & unit & $5.00 \times$ & 10.00 & & 50.00 \\
\hline 3 & Mobil & 2 & unit & $5.00 \times$ & 10.00 & & 50.00 \\
\hline & Jumlah & & & & & & 252.50 \\
\hline
\end{tabular}


Tabel 4. Kapasitas parkir SDN Joglo 76

\begin{tabular}{|c|c|c|c|c|c|c|c|}
\hline \multirow[t]{2}{*}{ No } & \multirow{2}{*}{$\begin{array}{c}\text { Jenis } \\
\text { Kendaraan } \\
\text { Sepeda ontel }\end{array}$} & \multirow{2}{*}{\begin{tabular}{|c|}
$\begin{array}{c}\text { Jumlah } \\
\text { Kendaraan }\end{array}$ \\
61 \\
\end{tabular}} & \multirow{2}{*}{$\begin{array}{c}\text { Satuan } \\
\text { unit }\end{array}$} & \multicolumn{3}{|c|}{$\begin{array}{l}\text { Perhitungan kapasitas setelah } \\
\text { lahan diatur }\end{array}$} & \multirow{2}{*}{\begin{tabular}{|r} 
Luas (m2) \\
45.75 \\
\end{tabular}} \\
\hline & & & & $0.50 \mathrm{x}$ & $1.50 \times$ & 61 & \\
\hline & Sirkulasi & & & 152.50 - & 45.75 & & 106.75 \\
\hline & Sepeda motor & 26 & unit & $0.75 x$ & $2.00 \mathrm{x}$ & 26 & 39.00 \\
\hline & Sirkulasi & & & 50.00 - & 39.00 & & 11.00 \\
\hline & Mobil & 2 & unit & $2.50 \mathrm{x}$ & $5.00 \times$ & 2 & 25.00 \\
\hline & Sirkulasi & & & 50.00 - & 25 & & 25.00 \\
\hline & Jumlah & & & & & & 252.50 \\
\hline
\end{tabular}

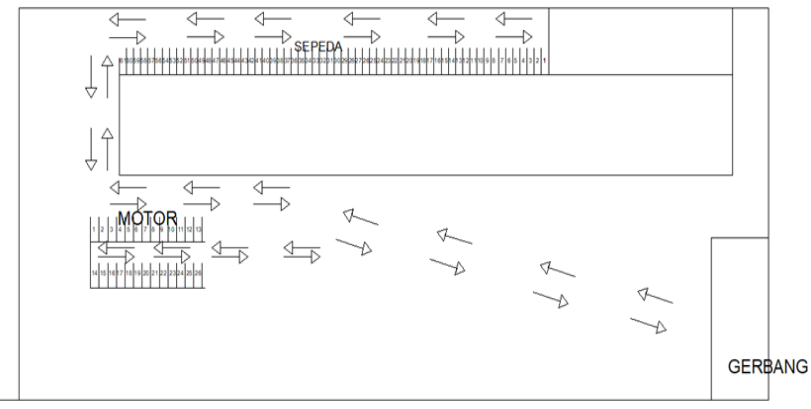

Gambar 7. Skema Parkir pada SDN Joglo 76

Dengan cara yang sama untuk lokasi penelitian yang lain dihitung, hasilnya dapat dilihat pada tabel 5 .

Tabel 5. Luas lahan parkir dan kapasitasnya

\begin{tabular}{|r|l|r|r|r|r|r|r|r|}
\hline \multirow{2}{*}{ No } & \multirow{2}{*}{ Nama Sekolah } & \multirow{2}{*}{$\begin{array}{c}\text { Lahan } \\
\mathbf{( m 2} \text { ) }\end{array}$} & \multicolumn{2}{c|}{$\begin{array}{c}\text { Kapasitas sebelum } \\
\text { diatur sesuai kebutuhan }\end{array}$} & \multicolumn{2}{|c|}{$\begin{array}{c}\text { Kapasitas sebelum } \\
\text { diatur (unit) }\end{array}$} \\
\hline & & & $\begin{array}{l}\text { Sepeda } \\
\text { motor }\end{array}$ & Sepeda & mobil & Sepeda & $\begin{array}{l}\text { Sepeda } \\
\text { motor }\end{array}$ & mobil \\
\hline 1 & SDN Joglo No 76 & 252.50 & 50 & 20 & 2 & 61 & 26 & 2 \\
\hline 2 & SDN Mojosongo 2 & 98.75 & 14 & 12 & 0 & 16 & 15 & 2 \\
\hline 3 & SDN Sumber 2 & 70.00 & 0 & 12 & 2 & 0 & 12 & 2 \\
\hline 4 & SDN Bulukantil & 146.00 & 30 & 6 & 2 & 38 & 6 & 2 \\
\hline 5 & SDN Tugu Jebres & 86.00 & 50 & 10 & 1 & 51 & 12 & 1 \\
\hline 6 & SDN Sumber 5 & 149.00 & 55 & 7 & 2 & 64 & 8 & 2 \\
\hline 7 & SDN Nayu 77 & 101.15 & 16 & 10 & 1 & 20 & 16 & 2 \\
\hline 8 & SD Al Islam 3 Gebang & 140.00 & 40 & 6 & 2 & 51 & 8 & 2 \\
\hline 9 & SDN Purwodiningratan & 137.00 & 30 & 10 & 2 & 36 & 16 & 2 \\
\hline 10 & SD Kanisius Serengan & 109.00 & 25 & 6 & 1 & 30 & 8 & 2 \\
\hline & Rata-rata & $\mathbf{1 2 9}$ & $\mathbf{3 1}$ & $\mathbf{1 0}$ & $\mathbf{2}$ & $\mathbf{3 7}$ & $\mathbf{1 3}$ & $\mathbf{2}$ \\
\hline
\end{tabular}

\section{KESIMPULAN}

Dari hasil penelitian diperoleh kesimpulan sebagai berikut :1). Lokasi sekolah yang dekat dengan permukiman berpengaruh terhadap jumlah murid, dari sepuluh sekolah yang djadikan obyek penelitian didapatkan 10\% lokasi sekolah cukup dekat dengan permukiman, 20\% dekat dengan permukiman dan $70 \%$ sangat dekat dengan permukiman.
2). Kondisi tempat parkir bagi siswa yang membawa sepeda ontel kurang layak karena tidak diberikan tempat yang representatif , prosentase kondisi tempat parkir pada lokasi penelitian adalah 20\% kondisi kurang, 60\% kondisi sedang, 20\% kondisi baik. 3).Kebutuhan lahan untuk tempat parkir bagi siswa dan guru telah tercukupi, akan optimal jika di lakukan pengaturan parkir yang baik. Rata-rata dalam satu sekolahan membutuhkan lahan parkir seluas $129 \mathrm{~m}^{2}$, dengan kapasitas untuk sepeda ontel 37 unit, 13 sepeda motor dan 2 mobil.

\section{UCAPAN TERIMA KASIH}

Puji syukur Alhamdulilah kami panjatkan kehadirat Allah Tuhan Yang Maha Esa, atas limpahan rahmat dan hidayahnya sehingga kami dapat menyelesaikan penelitian ini. Terima kasih kami haturkan kepada Universitas Tunas Pembangunan Surakarta melalui Direktorat Riset Pengabdian Masyarakat dan Publikasi UTP Surakarta yang telah membiayai penelitian ini.

\section{DAFTAR PUSTAKA}

Pendidikan Dasar dan Pendidikan Menengah

Kementerian Pendidikan dan Kebudayaan,

"Data Pokok Pendidikan Dasar dan

Menengah Direktorat Jenderal Pendidikan

Anak Usia Dini”,

https://dapo.dikdasmen.kemdikbud.go.id/sp/

2/036100

Farida Rahmawati, "Standard parkir", https://www.academia.edu/15374101/Standa r_parkir 
Direktorat Bina Sistem Lalu-lintas Angkutan Kota, Direktorat Perhubungan Darat, (1998), Pedoman Perencanaan dan Pengoperasian Fasilitas Parkir

Undang-Undang Republik Indonesia Nomor 1 Tahun 2011, "Perumahan Dan Kawasan Permukiman".

Departemen Perhubungan Direktur Jenderal Perhubungan Darat, Keputusan Direktur Jendral Perhubungan Darat Nomor: 272/HK.05/DRJD/96 tahun 1996, "Pedoman Teknis Penyelenggaraan Fasilitas Parkir".

Undang-undang Lalu lintas No.272 tahun 1996, "Status Parkir".

Lindawati MZ, (2012), “Analisis Kebutuhan dan Penataan Ruang Parkir di Kampus Universitas Baturaja”, Jurnal Teknika volume 2 nomor 3, Maret 2012

Mukhardi, Virgo Trisep Haris, Fadrizal Lubis, (2018), Analisis Areal Parkir pada SMK Negeri 5 Kota Pekanbaru", Jurnal Teknik volume 12 nomor 2, Oktober 2018

Alfred Rodriques Januar Nabal, (2014), "Evaluasi Kebutuhan Lahan Parkir pada Area Parkiran Kampus Fisip Universitas Atma Jaya Yogyakarta", Jurnal Teknik Sipil volume 13 nomor 1, Oktober 2014

Andi Budi Prasetyo, (2019), “Analisis Kebutuhan dan Kapasitas Area Parkir di Mall Solo Square Kota Surakarta”. Universitas Tunas Pembangunan Surakarta. 